\title{
Inscripciones callejeras en tiempo de malestar: un análisis etno-semiótico de imágenes del estallido social en Chile
}

Street inscriptions in times of discontent: An ethnosemiotic analysis of photos during the social outbreak in Chile

Juan LE BERT

Universidad de Chile, Chile

Departamento de Antropología

jlebertmontaldo@gmail.com

Maximiliano SOTO

Universidad de Valparaíso, Chile

Instituto de Historia y Ciencias Sociales

maximiliano.soto@uv.cl

\section{Resumen}

La práctica de caminar es un acto de interacción que estimula nuestros sentidos de percepción y que nos ayudan a leer la ciudad. Si nos concentramos particularmente en el sentido de la vista, podemos reconocer etnográficamente las marcas inscritas sobre muros, monumentos, esquinas, semáforos, estaciones de metro. Diferentes marcas escriturales que, a modo de contexto, dan cuenta de eventos asociados al estallido social vivido en Santiago, Chile, durante los últimos meses del 2019. De hecho, al caminar por las calles de Santiago podemos observar múltiples marcas que nos interpelan, imágenes y frases que, en síntesis, transmiten el fin de un proyecto histórico, o la sensación de un malestar social acumulado por muchas décadas, y definido colectivamente como el malestar de vivir bajo una subjetividad liberal que se manifiesta desde una comprensión de normalidad asociada a estilos de vida. El presente artículo, que se encuentra en progreso, tiene el objetivo de visibilizar el cuestionamiento de esta normalidad mediante una lectura etnosemiótica, la cual busca decodificar los signos y estilos que le dan cuerpo a los múltiples mensajes que expresan el malestar general de la sociedad frente a un estilo de vida identificado con el "modelo neoliberal", y que se proyectó en cada una de las fotografías que tomamos durante el período del estallido social, en los entornos cercanos a la "Plaza Italia-Baquedano-Dignidad" en Santiago, Chile.

Juan LE BERT y Maximiliano SOTO

Inscripciones callejeras en tiempo de malestar: un análisis etno-semiótico de imágenes del estallido social en Chile

Sur y Tiempo. Revista de Historia de América, №3, enero-junio 2021, pp. 66-85.

ISSN 2452-574X

DOI: $10.22370 /$ syt.2021.3.2686 
Palabras claves: etnografía; etnosemiótica; arte callejero; malestar; Santiago de Chile

\begin{abstract}
The practice of walking is an act of interaction which stimulates our senses of perception and helps us to read the city. If we concentrate particularly on the sense of vision, we can recognize ethnographically the signs written in walls, monuments, corners, traffic lights, subways. Different scriptural signs which, in the manner of the context, give a testimony of the social rebellion lived in Santiago, Chile, during the last months of 2019. In fact, while walking through the streets of Santiago we can observe multiple signs which are calling us, images and sentences which, in synthesis, transmit the end of an historical project, or the sensation of a social discontent accumulated during various decades, defined collectively as a discontent of living under a liberal subjectivity that manifests itself from a comprehension of normality associated to different life styles. The aim of the present article, a work in progress, is to visualize the questioning of this normality through an ethnosemiotic lecture, which tries to decode the signs and styles which give more substance to the corpus of the multiple messages that express the discontent contained in a society facing a life style identified as the neoliberal model which is projected in each one of the photos taken in the surroundings closed to the "Plaza Italia-BaquedanoDignidad" in Santiago, Chile.
\end{abstract}

Keywords: ethonography; ethnosemiotic; Street art; discontent; Santiago de Chile

"La relación del hombre que camina con su ciudad, con sus calles, con sus barrios, ya le sean estos conocidos o los descubra al hilo de sus pasos, es primeramente una relación afectiva y una experiencia corporal”, (Le Breton, 2018: 174).

\title{
Introducción
}

Cada ciudad contiene experiencias distintas configurando un soporte que, a modo de texto, reúne trazos, marcas y escritos que los sujetos inscriben en el espacio urbano. En este texto urbano es posible identificar mensajes que se expresan a través de grafitis, tags y stencils, expresiones de un arte callejero territorial (Rodríguez-Plaza, 2001; 2011) que figura en muros, vitrinas, semáforos, locales comerciales, por mencionar algunos ejemplos, y que interpelan a los sujetos que las 
observan.

Si ponemos como ejemplo la ciudad de Santiago, y nos situamos temporalmente en el contexto del estallido social iniciado el pasado mes de octubre 2019, podemos observar que las inscripciones urbanas dejadas son posibles de ser cartografiadas etnográficamente. Un método que desde el caminar-observante permite al etnógrafo reproducir, desde estas marcas, el clima vivido por el país durante días en que se puso entre paréntesis la noción de normalidad social, para expresar demandas que cruzan las injusticias económicas, sociales y culturales. Este paréntesis que marca un hito histórico en el país, lo exploramos a partir de un registro fotográfico que, en la mayoría de las imágenes, fue reunido durante los días del paréntesis o del estallido, sin ánimo de teorizar ni interpretar lo que iba sucediendo, sino en el ánimo de vivir intensamente los significados que de manera colectiva y con una resonancia intensa, fueron vividos por la mayoría de la población chilena durante esa catarsis social.

Partimos de la base que las imágenes no responden a una codificación azarosa sino más bien a ritos de inscripción. De hecho, las imágenes fotografiadas dan cuenta de una inscripción que, a modo de marca, permanece y se apropia de un nicho para hacer dialogar la calle con la escritura, y lo escrito con el observador. Las imágenes registradas nos permiten identificar estilos $y$ expresiones que se sobreponen a modo de palimpsesto (intertextualidad), respondiendo a trazos de figuras que les preceden y que podemos identificar en los alrededores de la Plaza Italia-Baquedano (hoy plaza de La Dignidad) como son la Av. Alameda, Av. Vicuña Mackenna y la calle Bustamante.

En este ejercicio de cartografía etnográfica se hace necesaria la búsqueda de referentes teóricos que permitan guiar el análisis. Entre estos referentes que operan como carta de navegación podemos señalar la etnosemiótica (Marsciani, 2016), la semiósis social (Verón, 1987), la semiótica cultural (Lotman, 2009: 2000), la semiología de la imagen (Barthes, 1964: 2015) y la estilística discursiva (Bajtín, 1981: 2011). Referentes que nos ayudarán con nuestro objetivo de visibilizar y decodificar, mediante una lectura etnosemiótica, los múltiples mensajes que expresan el malestar de vivir bajo una subjetividad liberal. En este artículo hemos querido ilustrar a través de las connotaciones de tres imágenes, la multiplicidad de interpelaciones gráficas y textuales que se configuran en torno al malestar de la sociedad, en el contexto del estallido social.

\section{Experiencias en la ciudad}

Los habitantes de la ciudad se diferencian en la manera cómo viven su cotidianidad en la trama urbana, hay por lo tanto una diferenciación en la experiencia fenomenológica con la ciudad, una experiencia que estimula la 
interacción desde los sentidos, y claramente donde la visión y la audición resaltan por sobre los otros sentidos al momento de leer y escuchar la ciudad. "La ciudad no está fuera del hombre, sino en él, impregnando su mirada, su oído y todos los demás sentidos" (Le Breton, 2018: 175).

Al comenzar a caminar y observar en estos lugares de reconocimiento colectivo, las marcas del estallido, gravita desde un primer momento la emocionalidad de las imágenes transformadas en redefiniciones de la normalidad y vivencia de lo social. Imágenes contenedoras de signos asociados a un malestar de subjetividad liberal, denunciando que hemos vivido bajo un imaginario y un proyecto de sociedad que no solo se sostiene en un paquete de medidas económicas, sino que trata de la instalación de una normalidad que se expresa en la internalización de un estilo de vida, el cual legitima el proyecto neoliberal.

Hay que relevar el contexto en el que se dan lugar estos mensajes, se trata de una fecha icónica para los movimientos sociales y para las manifestaciones de gran convocatoria social, que queda como un evento que marca un antes y un después en la reciente historia de Chile. Se trata de poner en cuestión un modo de vida que se desprende de un modelo social y económico instaurado desde la época de la dictadura (1973-1990), y este ejercicio de reflexión y catarsis colectivo se llevó a cabo a través de una multiplicidad de manifestaciones, entre las cuales hemos particularizado el análisis, en los rayados y estéticas que quedaron plasmados en las arterias principales de la capital.

Se trata de huellas e inscripciones sobre el espacio urbano, en donde se interpela constantemente al habitante (el Otro implícito de la interpelación) y su clima de malestar, el que hace referencias a una memoria larga de la cultura, la cual se ha decantado en la metáfora de instauración de una normalidad social, o de un estilo de vida que se vivió como la única realidad posible. Este malestar imbrica tanto la cultura de la intimidad personal y familiar, como las imágenes y símbolos de la cultura de lo nacional y las narrativas que la han articulado.

La distinción clave es que esta experiencia no es la misma de acuerdo a la manera de vivirla y proyectarla en distintas comunas y sectores sociales, en ese sentido la ciudad no se vive sino en la multiplicidad de ciudades que emergen desde la experiencia de los grupos sociales que comparten rutinas similares, generando a su vez patrones de interpretación de lo que significa habitar la ciudad, de manera diferenciada. Pero también se vive la ciudad de manera común, en aquellos puntos en que la convergencia social de distintos mundos de vida (Schütz, 1995) o cotidianidades reconocen lugares de encuentros de carácter más colectivo e integrador, como sucede emblemáticamente con la Plaza Italia-Baquedano o Plaza Dignidad. 


\section{La emocionalidad y sus ritos de inscripción}

La marca o el pastiche inscrito en las murallas reconfigura la emocionalidad para llevarla a una inscripción escrita y visible que, en su conjunto, da cuenta de mensajes que expresan un sentido de malestar: "Evade"; "No son 30 pesos, son 30 años"; "Se metieron con las generaciones que no tienen nada que perder. Ni casa, ni trabajo, ni jubilaciones, no tenemos nada, ¿qué miedo va a haber?”

La inscripción que podemos observar en un muro, en un monumento, en una puerta, por mencionar algunos ejemplos, responde a un proceso escritural que se nos presenta como un palimpsesto, dificultando el poder identificar qué es lo primero o cuál fue la primera escritura. Al seguir a Roland Barthes vemos que su definición de escritura nos da un margen de orientación al señalar que: "La escritura es precisamente este espacio en el cual las personas de la gramática y los orígenes del discurso se mezclan, se confunden, se pierden hasta lo irreparable: la escritura es la verdad, no de la persona (del autor), sino del lenguaje. Es por eso que la escritura va siempre más lejos que la palabra" (Barthes, 2015:14, traducción de los autores). Una primera definición de escritura que nos ayuda a comprender las marcas del estallido que se observan en la calle como espacio de tránsito y de encuentro, marcas que develan una forma de escritura pública, sobre la página saturada de control y de resguardo, que son los espacios urbanos de la convivencia social durante los últimos decenios.

Cabe diferenciar en el conjunto de las imágenes y frases, y de manera general, una interpelación del malestar donde los mensajes críticos hacia el Otro que sostiene la normalidad se asocian al orden institucional-represivo, a las distinciones de clases y privilegios asociados (o las "burbujas" en que vive el privilegio como metáfora central del malestar) y las múltiples formas de violencia simbólica y segregación, donde destaca el malestar que se desprende de la violencia de género, por mencionar algunas derivadas principales 1 .

Por otra parte, la masa que participa de esta experiencia de apropiación del espacio social se reconoce en el plano de las interacciones y el encuentro entre subjetividades, masa que se ha rebelado de la actual expresión del espacio público o del control del imaginario social que construyen cotidianamente los medios de comunicación de masas (los mismos medios pasan a ser objetos de la rabia y el malestar de una masa espontánea y viral, que está consciente de que los medios son y han sido funcionales al poder económico de las elites). Estos medios funcionales al proyecto neoliberal se han caracterizado por asimilar todo evento y significación del

1 Chile es una muestra clara de segregación urbana. Se si hace un recorrido por los instrumentos de planificación de Santiago se aprecia que en los últimos 30 años esta ciudad ha crecido tanto superficial como demográficamente de manera considerable, principalmente gracias a las políticas 
malestar colectivo al lenguaje de la banalización o espectacularización de la protesta social en general. Y finalmente, podemos observar que una emocionalidad de malestar se manifiesta y estalla en la calle, y permanece en la calle. Una emocionalidad manifiesta que no tiene lenguaje y que es la base del contagio de una masa (Canetti, 2013).

El malestar también puede analizarse en el cansancio que genera este lenguaje de banalización, que da cuenta de todos y cualquier evento de la vida social en el deseo de satisfacer a amplias audiencias, comprometiendo la multiplicidad de esferas del mundo de los distintos sectores sociales, y reduciendo todo a la sujeción al consumo y a la producción social de la indiferencia.

En el estallido se recupera la palabra, se recupera la misma noción de realidad, en el asombro de verse como comunidad a distintos grupos de la sociedad que en general se han simbolizado en la violencia y en la tensión. Es un mensaje que se inscribe en un acto ético al producir palabras en un sentido más o menos determinado y a la vez con unas referencias más o menos determinadas desde el público tribal que escribe (Verón, 2003). Aparece entonces en la escena social una subjetividad en resistencia al dominio de significaciones imaginarias que han conformado la normalidad de los últimos treinta años.

Una imagen ilustrativa la podemos ver al presenciar la bandera mapuche que aparece como significante central y articulador del malestar en la cultura nacional. La bandera mapuche rebautiza la historia en el lenguaje del marginado, violentado, distorsionado a través de toda la historia de la república. El pueblo mapuche se transforma en el significante central de una multiplicidad de expresiones de malestar de la sociedad.

La bandera mapuche se instala como baluarte que sostiene al todo pintarrajeado general Baquedano, imagen que enerva a la sensibilidad conservadora la cual demanda que los militares vuelvan a la calle, en su añoranza a la época de la dictadura. Por otra parte, en la complejidad de esta contingencia opera el retorno de un lenguaje reprimido, en la escena de ocupación social del símbolo de encuentro del habitante de Santiago, donde se aprecia repetidamente la toma de Plaza Italia, donde continuamente vuelve a izarse la bandera mapuche y se vuelven a manchar las estatuas con múltiples colores. La plaza Italia-Baquedano se transforma en la plaza de la Dignidad, donde flamea la bandera mapuche en todo su esplendor (ver figura 1).

que han desregulado y han ampliado el límite urbano, generando una ciudad morfológicamente discontinua, segregada y altamente desigual en cuanto a la accesibilidad infraestructura y servicios. 


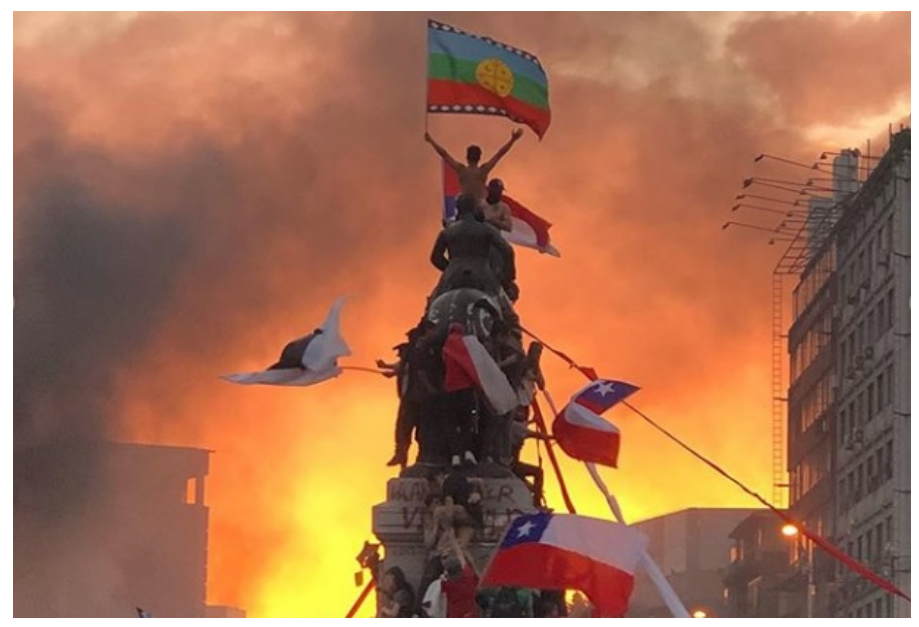

Figura 1: "La bandera mapuche sobre el Monumento al General Baquedano, Plaza Italia".

(https://www.fmdos.cl/noticias/historia-detras-foto-viralmarcha-mas-grandechile/).

Se trata, por lo tanto, de una lucha entre diferentes sistemas de signos, el ciudadano-a se convierte en un semiótico-a de fuerte raigambre intuitiva, considerando que la semiótica socio-espacial busca configurar los sistemas de signos que construyen la normalidad de la vida social, de este modo hace posible la transgresión de significaciones que nos permite otra forma de soñar el habitar y simbolizar la realidad. Una distinción que se obtiene desde un ejercicio de etnosemiótica al permitir "reconstruir un campo relacional (en términos de relaciones de valor y narrativas) y consentirles de presentarse como un mundo, en la escena de un discurso posible" (Marsciani, 2016: 2, traducción de los autores). Y de una semiótica cultural que nos ayuda a decodificar lo que se nos presenta frente a los ojos y a tener ojo con lo supuestamente dado. “...la semiótica que juzga completamente natural y elemental considerar cualquier texto como algo dado, sino en calidad de objeto de desciframiento, ante todo prestando atención a los mecanismos codificantes que lo generaron" (Lotman, 2009: 16). Dos subdisciplinas que ayudan al observador/caminante a comunicarse con las imágenes que contienen el malestar cotidiano inscritos en el arte callejero.

Se trata también de fuerzas en tensión, apropiaciones y redefiniciones en un campo de lenguaje que implica el hacerse cargo de términos que deben ser sublevados, y es lo que encontramos en las inscripciones en el espacio social, en el lenguaje de Bajtín:

Un lenguaje unitario común es un sistema de normas lingüísticas. Pero estas normas no constituyen un imperativo abstracto; se trata más bien de las fuerzas generadoras de la vida lingüística, fuerzas que 
luchan por sobreponerse a la heteroglosia del lenguaje, fuerzas que unifican y centralizan el pensamiento ideológico-verbal y crean así, dentro de un lenguaje nacional heteroglota, el núcleo lingüístico firme $\mathrm{y}$ estable de un lenguaje literario oficialmente reconocido o bien, defienden un lenguaje ya formado de la presión siempre creciente de la heteroglosia (Bajtín, 1981: 270-271, traducción de los autores).

En la composición de casi todas las enunciaciones que pronuncia una persona social, desde una respuesta breve en un diálogo casual hasta grandes obras verbalesideológicas (literarias, eruditas y otras), se puede identificar un número significativo de palabras de las que, de manera explícita o implícita, se admite que son ajenas y que se transmiten por una variedad de medios. Dentro del ámbito de casi cada enunciación hay una interacción intensa y una lucha que se libra entre las palabras de uno y las de otro, un proceso en el que se oponen o se animan entre ellas dialógicamente.

La enunciación así concebida es un organismo considerablemente más complejo y dinámico de lo que parece cuando está construido simplemente como algo que articula la intención de la persona que la pronuncia, y eso es justamente lo que puso en operación el estallido social, una trama de lo subjetivo que tiene evidentemente un carácter colectivo, y que no teniendo lugar de inscripción, ni en los lenguajes políticos ni mediáticos de la sociedad, crea su propia atmósfera de subversión y de significación, en la ocupación y paralización de la ciudad durante una estética de carnaval urbano y de recuperación del sentido de vivir en sociedad, que implicaron las vivencias del estallido.

Todas las lenguas de la heteroglosia, cualquiera que sea el principio que subyace en ellas y que las hace únicas, son puntos de vista específicos sobre el mundo, formas para conceptualizar al mundo en palabras, en visiones del mundo específicas, cada una caracterizada por sus propios objetos, significados y valores. Como tal, todas podrían estar yuxtapuestas entre sí y podrían complementarse la una a la otra, contradecirse entre sí y estar interrelacionadas dialógicamente.

Es así como se encuentran entre sí y coexisten en las conciencias de gente real, pero en primer lugar y, sobre todo, en la conciencia creadora de la gente que escribe novelas. Por lo tanto, estas lenguas viven una vida real, luchan y evolucionan en un medio ambiente de heteroglosia:

[L]as fuerzas centrípetas en la vida del lenguaje, incluidas en un "lenguaje unitario", funcionan desde la heteroglosia. En cualquier momento dado de esta evolución, el lenguaje está estratificado no solo en dialectos lingüísticos en el sentido estricto de la palabra (conforme a los hacedores de lingüística formal, en especial de la fonética), sino también -y para nosotros este es el punto central- en lenguajes que 
son socio-ideológicos: los lenguajes de grupos sociales, los lenguajes "profesionales" y "genéricos", los lenguajes de generaciones, y así sucesivamente. [...] Una vez efectuadas la estratificación y la heteroglosia, no solo son una constante estática de la vida lingüística, sino lo que asegura su dinámica: la estratificación y la heteroglosia se amplían y profundizan siempre y cuando el lenguaje esté vivo y en desarrollo (Bajtín, 1981: 272-273, traducción de los autores).

Por otro lado, y a través de las interpelaciones imaginarias y textuales del estallido se desprende, o configura, un soporte sobre el cual se aplica una técnica metodológica que Roland Barthes desarrolló en torno a lo que denominó retórica de la imagen: "¿la representación analógica (la copia) puede producir verdaderos sistemas de signos y no sólo simples aglutinaciones de símbolos? ¿Un código analógico -y no sólo digital- es concebible? (Barthes, 1964:40, traducción de los autores). Un cuestionamiento a realizar ante las imágenes contenedoras de malestar, y a la vez contenedoras de palabras que responden a sistemas de signos más que de símbolos reunidos.

Desde una retórica de la imagen, y en diálogo con un punto de vista fenomenológico, cabe destacar el dominio de vivencias observadas en estos últimos meses, y, sobre todo, desde la marca inscrita por el estallido social de octubre de 2019, allí se destaca principalmente una suerte de emocionalidad colectiva que utiliza al espacio público como una página donde inscribe su malestar. Se trata de una pulsión por salir del espacio íntimo y privado a lo público. Desde el romper con las codificaciones básicas de los flujos de la ciudad, y generar el evento que admite la expresión de diferentes temporalidades asociadas a públicos diversos. Es así como actores de diferentes edades se encuentran discutiendo sobre la historia y el devenir de la sociedad chilena. Podemos identificar capas de textualidades que dialogan entre sí, el hecho de interpelar al espacio lleno de capas y complejidades se asocia con la idea de un espacio social que funciona dentro de una cierta normalidad, cuestionada, en el marco de una emoción central que busca desarticular una máquina de producción de subjetividad neoliberal.

De esta manera las interpelaciones observadas en la calle, como espacio de tránsito y de encuentro, develan una forma de codificación que nos habla de una etno-semiótica del espacio urbano. Exploramos la traducción del malestar en estas formas de inscripción. En las marcas observables que cohabitan, y que incluso se sobreponen configurando un palimpsesto, a modo de acoplamiento de estéticas, que enriquece la significación y la sitúa sobre todo en la conciencia de una comunidad de intérpretes que ha habitado la historia de este país, y que, de manera esquizoide, ha aceptado un orden de cosas que se ha hecho insostenible, el cual se ha construido mediante las presiones y narrativas que conforman la normalidad imaginaria del 
habitar.

La escritura del estallido social se observa escrita en el espacio social. Se puede observar una especie de heteroglosia (Bajtín, 1981) que habita en el espacio urbano. El orden ideológico del discurso inscrito en la calle busca sensibilizar al Otro Implícito (la ciudadanía en la figura del caminante o del transeúnte) a través de una sola voz que pasa del anarquismo al autoritarismo. El Orden y desorden se encuentran en una semiótica social que dialoga entre estas dos sensibilidades binarias, las cuales se observan celosamente para imponer sus estrategias de reproducción y de dominación sobre la ciudad que alberga el espacio social y que irrumpe el malestar a través de tags y graffitis que se manifiestan en soleras, muros, parques, edificios, bancos de la Gran Ciudad. La voz de la institucionalidad que por años se manifiesta en bancos, compañías de seguros, universidades, edificios públicos, ahora cierran sus puertas por pánico o miedo al desorden, y sobre sus puertas unas nuevas voces buscan inscribir sus escrituras.

El espacio urbano ya está escrito a través de una distribución de los poderes políticos, económico, sociales y religiosos. Algo que, por ejemplo, se puede observar desde la plaza central. El espacio social codificado desde las estéticas y diferenciaciones mercantiles, el mercado aparece también como un género estético donde habita el Otro implícito del poder.

Como hemos insistido, las escrituras que se inscriben en el espacio urbano dan cuenta de un malestar. Y la estrategia del orden es de primero reprimir y luego hacerse cargo de la inmensa demanda ciudadana que busca hacerse escuchar en el espacio público. La plaza Italia-Baquedano-Dignidad es un ejemplo para entender cómo la limpieza opera. Se limpia el tótem central de las protestas y del estallido social. Queda posteriormente registrado en la memoria colectiva, la figura del Presidente sacándose una foto en ese lugar icónico, donde se jugaron todas las marcas y signos de protesta en su contra. Los signos que no tienen expresión oficial aparecen como voces fantasmáticas y amenazantes al orden constituido, conforman un lenguaje desde otra emocionalidad que habita en la calle y que habla desde la calle (ver figura 2).

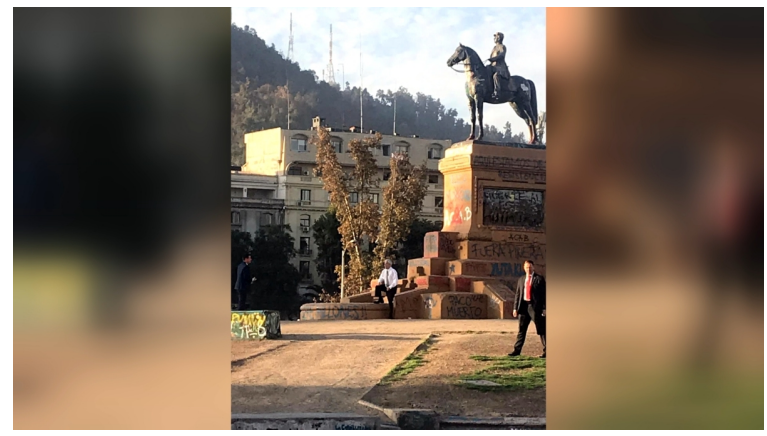

Figura 2: "El Presidente sentado en la Plaza Italia y abajo del Monumento del 
General Baquedano".

(https://www.t13.cl/noticia/politica/la-sorpresiva-aparicion-pinera-plaza-italiasaludo-carabineros-y-se-tomo-fotografias)

\section{Análisis ilustrativo del malestar en tres imágenes}

Los discursos donde se inscriben las miradas ¿a quién miran, a qué lector implícito? Ambas preguntas son guiadas por los tres momentos que Bajtín propone: "Los tres momentos, a saber, el contenido temático, el estilo y la construcción compositiva, están inseparablemente unidos en la totalidad de la expresión y se definen unívocamente por la especificidad de la esfera de comunicación dada" (Bajtín, 2011: 11). Tres momentos que acompañarán el ejercicio, e intento, de decodificación de las tres imágenes seleccionadas.

\subsection{Amor al Pueblo}

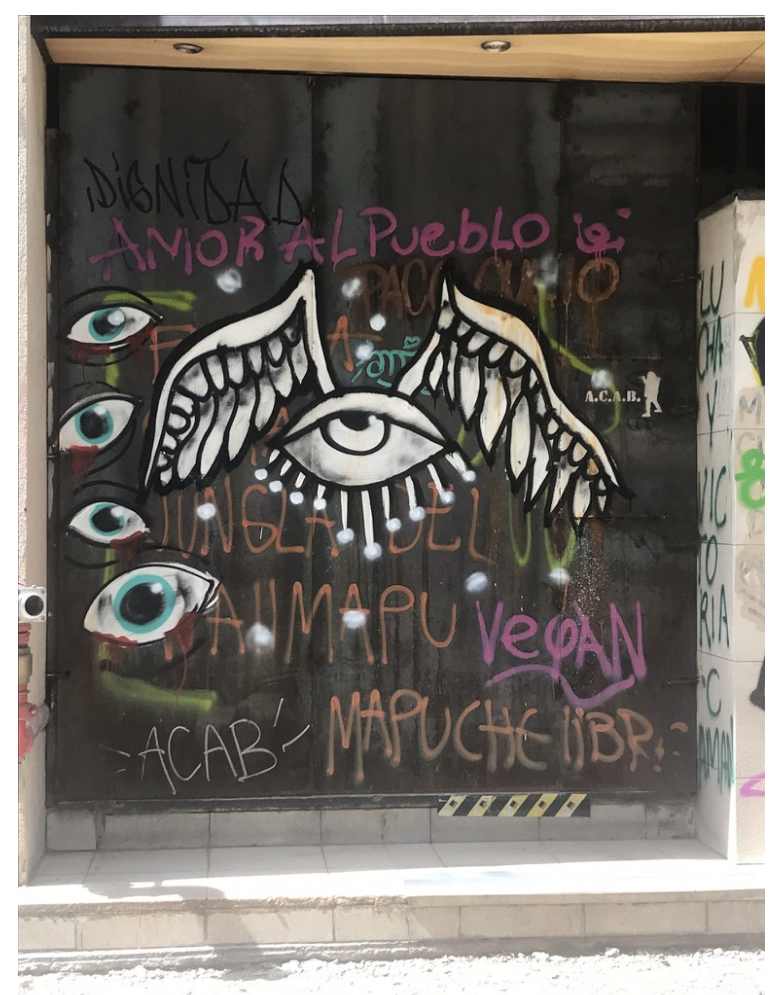

Figura 3: "Amor al Pueblo".

(Foto J. Le Bert. 30-10-2019) 
Lo icónico de los ojos², la represión pasa a lo sublime dejando claro que la policía cumple la función de la tortura, con todas las connotaciones que está presente en la narrativa política chilena, el largo período de la represión, que se vio marcado por la transición y las formas que siguieron encubriendo las contradicciones y conflictos que se "destapan" en el estallido, y que no fueron advertidos por la derecha o por los mismas agencias de poder, lo que acentúa el carácter cínico de la dominación ideológica.

Ojos: ¿Hacia dónde van nuestros mártires? ¿En qué espacio imaginario se pueden redimir? ¿Cómo se transforman en parte de una historia marcada por el sacrificio y por el lenguaje de las creencias populares? El angelito, el inocente que parte con sus alas a ese lugar donde generará protección para los que sobreviven. La mirada del angelito es simbólica, es sólo un ojo a medio abrir yendo hacia el campo de lo sagrado, rostro custodiado por otros ojos que lo rodean, es una mirada que se instala en otro campo de significación, que está de todos modos sublimada en el discurso de lo religioso y de lo popular. La mirada simbólica de sólo el ojo del angelito.

El largo viaje de Patricio Kaulen, 3 la memoria o el referente está en la sensibilidad popular, no han muerto en vano y la energía que dejan esos ojos iluminan a los que siguen. El culto popular escribe la historia de otra manera, que es evidente para los suyos, pero indescifrable para el poder en su necesidad de normas y códigos que buscan borrar el acontecimiento. La referencia radica en la memoria popular.

\footnotetext{
2 La referencia a los múltiples casos de ojos dañados durante las manifestaciones, que llevaron a acusaciones de parte de los DDHH al Estado de Chile, siendo un caso icónico el de Gustavo Gatica.

${ }_{3}^{3}$ Largo viaje es una película coproducción de Chile y Argentina que se estrenó el 7 de agosto de 1967. Este largometraje fue dirigido por Patricio Kaulen, protagonizado por Emilio Gaete, Eliana Vidal y Enrique Kaulen. Un niño de los barrios pobres de Santiago de Chile vaga por la ciudad buscando su hermano muerto recién nacido («el angelito») para devolverle las alitas que cree que perdió en su velatorio, pues sin ellas, no podría entrar al cielo.
} 
3.2. Mujeres y animales no somos objetos del consumo patriarcal

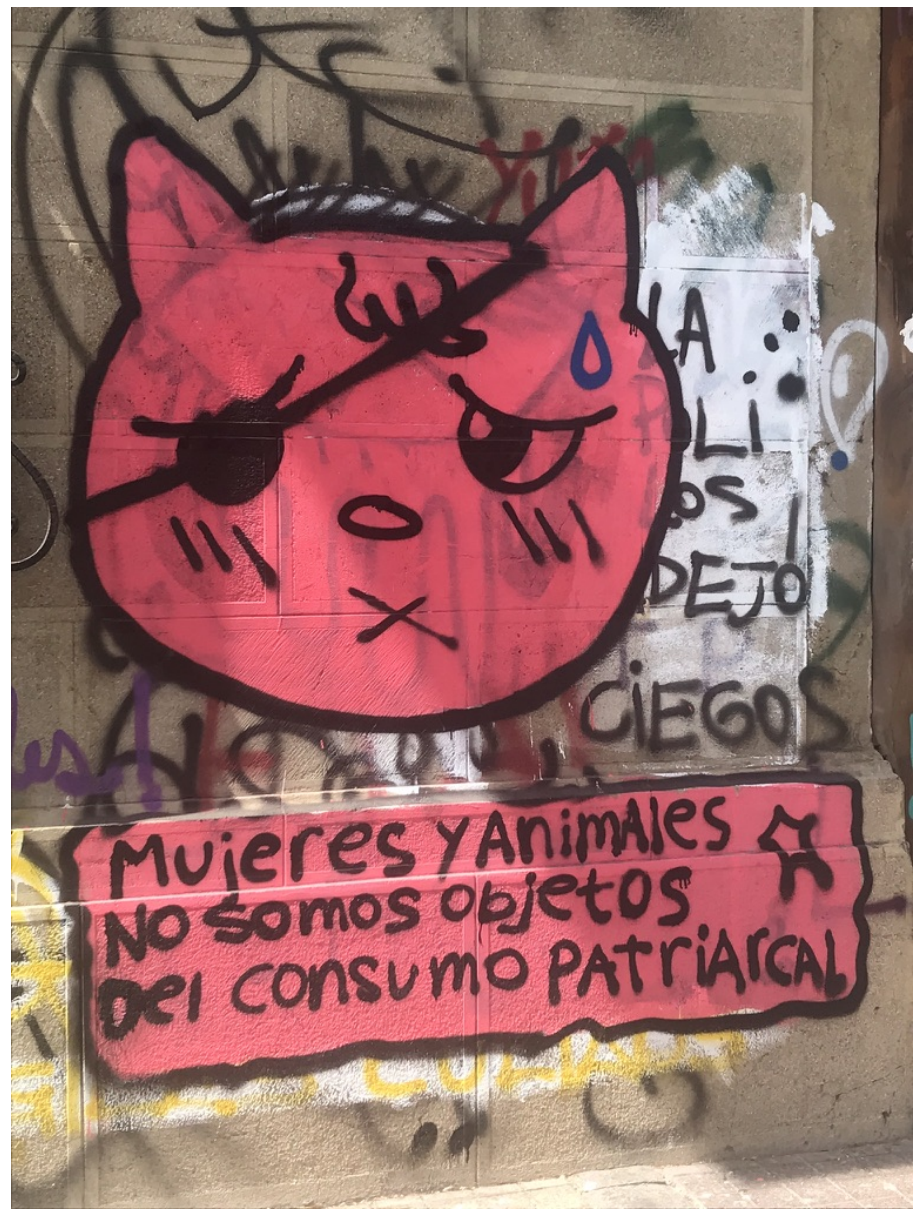

Figura 4: "Mujeres y animales no somos objetos del consumo patriarcal".

(Foto J. Le Bert, 30-10-2019)

La imagen del animal se sitúa en la posición de la víctima, no es la imagen desafiante de la estética de consumo, es la imagen de la figura castigada y sometida al deseo masculino o patriarcal, que no sólo se condensa en las figuras políticas masculinas, especialmente aquellas que recuerdan el período de la dictadura, sino en la dimensión cultural de la dominación masculina, que objetiva la presencia del otro o los campos de experiencia y de humanidad de la mujer y del reino animal.

La lectura de la imagen y el texto en este sentido inscribe el género en el mismo campo semántico de la naturaleza, controlada por la relación instrumental que se identifica con el deseo masculino. Hay una tendencia en este tipo de interpelación en el estallido, genera un mosaico que, como insistencia, aparece ligado al malestar de la cultura, en toda su intensidad.

La Gata interpela desde un lugar subyugado, su mirada desde el comic mantiene el lugar de la esclava del lenguaje del otro, las huellas de la represión la 
han mimetizado en la naturaleza y en la mujer, en la manipulación de la razón instrumental, en la degradación de la vida erótica, en la semántica de una interpelación que busca hacer conciencia de la lógica del sistema, de lo que ha provocado en ese rostro, como las huellas de los sobrevivientes, como un producto de la misma simbolización dominante. En ese marco se hace visible a través del comic el rostro de denuncia que reproduce los códigos del agresor, el lenguaje y la normalidad del agresor ha producido a una mujer apaleada, de la misma forma como se ha apaleado a la naturaleza. Esa es su referencia.

\subsection{Lucha como Gladys}

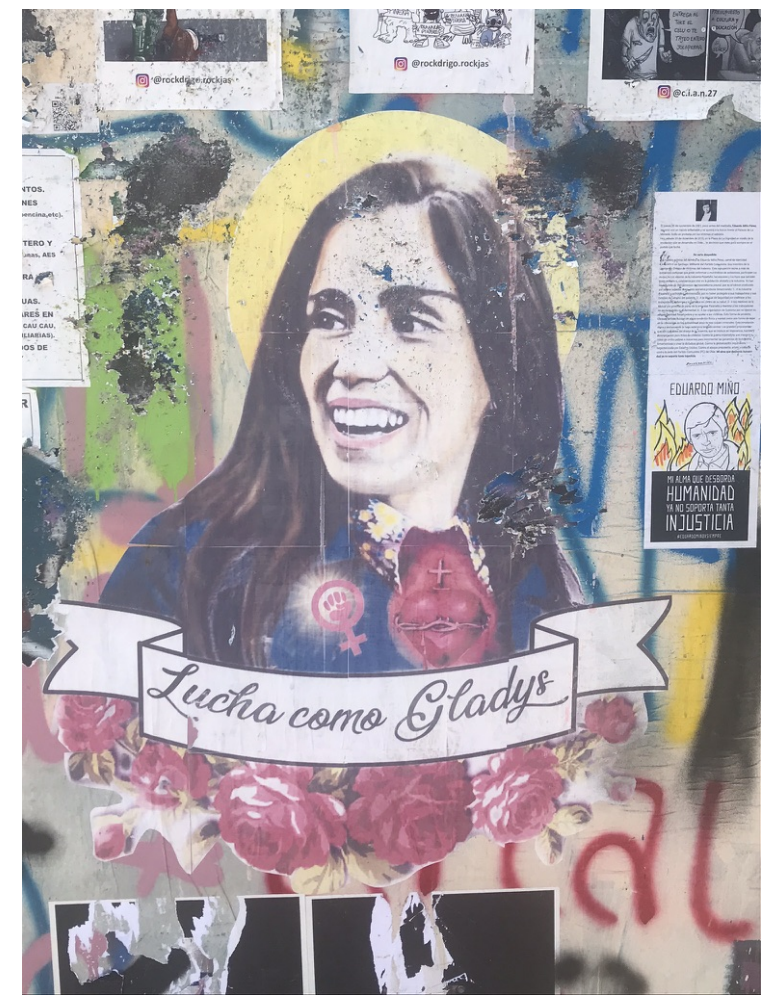

Figura 5: "Lucha como Gladys"

(Foto J. Le Bert, 30-10-2019)

La carga de Gladys, comunista, de una sola línea, implacable, resistente, respetada una vez muerta por la misma derecha, se sabía lo que iba a defender, se sabía que no iba con el interés bajo la manga, es parte icónica de un imaginario que se disipa en el consumo, pero que reaparece con fuerza como imagen de la mujer. Sin embargo, no se trata solamente de la imagen de la memoria de Gladys y de sus luchas, se trata también de una imagen sublime inscrita en la religiosidad popular, que admite una infinidad de mensajes junto a lo sagrado, la aureola de la santa y la leyenda; lucha como ella, incansable como ella, en el honor de lo íconos que forman 
parte de la memoria colectiva, y sobre todo, si se leen en el conjunto de interpelaciones, se trata del género, de la multiplicidad de luchas donde Gladys ocupa un lugar de privilegio.

La mirada santa, popular y alegre de Gladys. La mirada santa que está asociada a un pasado, a una sensibilidad colectiva, a una vanguardia irrenunciable. Por otro lado, en la risa de reojo de Gladys habría un otro que está fuera de la mirada del lector real pero que está en la intencionalidad de la mirada de Gladys, podría ser la mirada al compañero, o al Otro por el quien se interpela, la mirada colectiva de un fantasma que escapa a la mirada actual.

La mirada es una forma de codificación y de representación del sujeto, la mirada subjetiva al otro, la inscribe en un espacio imaginario, que en este caso acoge lo popular, lo popular que es un lenguaje, una forma de apropiación y de lectura de la experiencia.

La mirada que somete está en los medios, la mirada dominante que se ha hecho cargo de contar la historia. Pero re-nace la historia en el imaginario popular. Cuando la mirada está sometida a las representaciones que se han decantado de ella y no hay otra forma de zafarse de ellas sino a través de un desconocimiento, que busca hacerse en algún lugar aún inexistente.

El discurso inscrito en ella es el de la religiosidad popular, la acogida del mismo pueblo hacia su ícono, hacia su alegría que se proyecta en la sonrisa que acompaña a la mirada. El discurso religioso del corazón de Jesús, el corazón de lo sagrado es parte de su cuerpo y de la memoria de su cuerpo inscrito en la sensibilidad popular. El corazón y el símbolo de la mujer en su lado derecho. Los objetos simbólicos que reafirman su inscripción en la sensibilidad popular4.

Una inscripción simbólica en la sensibilidad religiosa popular es una mediación, es una fuerza bienhechora que protege y cuida a los mortales. Se hace un pacto con ella, es una imagen ejemplarizadora que da y a la que hay que retribuir, la

\footnotetext{
${ }_{4}$ "La devoción al Corazón de Jesús ha existido desde los primeros tiempos de la Iglesia, cuando se meditaba en el costado y el Corazón abierto de Jesús, de donde salió sangre y agua. La devoción al Sagrado Corazón está por encima de otras devociones porque se venera al mismo Corazón de Dios. Según la narrativa religiosa popular, fue Jesús mismo quien, en el siglo XVII, en Paray-le-Monial, Francia, solicitó, a través de una humilde religiosa, que se estableciera definitiva y específicamente la devoción a su Sacratísimo Corazón. El 16 de junio de 1675, se le apareció nuestro Señor y le mostró su Corazón a Santa Margarita María de Alacoque. Su Corazón estaba rodeado de llamas de amor, coronado de espinas, con una herida abierta de la cual brotaba sangre y, del interior de su Corazón, salía una cruz. Santa Margarita escuchó a nuestro Señor decir: 'He aquí el Corazón que tanto ha amado a los hombres, y en cambio, de la mayor parte de los hombres no recibe nada más que ingratitud, irreverencia y desprecio, en este sacramento de amor'. Con estas palabras nuestro Señor mismo nos dice en qué consiste la devoción a su Sagrado Corazón. La devoción en sí está dirigida a la persona de nuestro Señor Jesucristo y a su amor no correspondido, representado por su Corazón. Dos, pues son los actos esenciales de esta devoción: amor y reparación. Amor, por lo mucho que Él nos ama. Reparación y desagravio, por las muchas injurias que recibe sobre todo en la Sagrada Eucaristía" (Eliade, 1980).
} 
causa es lo que se evoca en el texto, y la causa tiene una lectura de la historia y de las injusticias que se reactualiza en el momento del estallido o el de la toma de la palabra, de la calle, de lo no-dicho que se dice por medio de la manifestación simbólica, del reencuentro con el otro, de la nostridad. Es un guiño a la lucha y al reencuentro con una demanda que queda siempre en la herida, en la degradación. Las metáforas de la dominación.

Gladys es la memoria; la mujer en su guiño al momento actual, la mujer que representa su lugar, la que no transa la lucha, la referencia histórica incluida en el imaginario de la derrota y al mismo tiempo en el sentido que ha quedado en la memoria popular, y que también ha sido inscrito en el lenguaje del poder como una alegoría del mal, desde la represión hasta hoy; la referencia es la memoria histórica.

La imagen de Gladys, dada su caracterización estética y su inclusión como ícono en el estallido social se inscribe como mujer, en otro universo de sentido, desde lo dicho de la religiosidad popular hasta las demandas de género en una mirada, un cuerpo y una historia que no se posicionó nunca por el lado de la dominación, en ello conforma un ejemplo en el imaginario de las nuevas generaciones donde queda inscrita su memoria como un ejemplo de disciplina, rebeldía y lealtad a su causa, lo que queda marcado en la misma leyenda que la resitúa; "lucha como Gladys".

\section{Conclusiones prematuras}

Desde el análisis desarrollado podemos afirmar que es difícil dar cuenta de las contradicciones que se expresaron en el estallido social de octubre 2019. Sin embargo, la etno-semiótica y la discursividad estilística nos ayudan a decodificar el sentido del estallido en diálogo con una amenaza al orden de la normalidad que es percibida desde el sistema dominante.

La referencia es una acumulación de experiencias que no ha sido visibilizada y que es la productora de la noción del malestar social.

El malestar es sentido como efecto general de la cotidianidad que genera la adaptación a una forma de producción social global que aparece como realidad a la que hay que de alguna forma adaptarse y responder de la manera más racional posible, lo cual no significa que los costos asumidos no sean sentidos en la forma de acumulación, de densidades, de líneas y devenires (Deleuze, 1989; Deleuze y Guattari, 2013) que no tienen la misma lógica y secuencia que el de la adaptación social. Son estas contradicciones las que hemos nucleado en la noción de malestar.

El sentido del malestar es leído desde los mismos productores como manifestaciones que tocan sus propios mundos de la vida, y en donde encuentran en la página urbana un lugar de inscripción más real que el que se experimenta en el sentido común o en la normalidad del mundo de la vida. 
Se trata de dejar una marca; 5 la orina o el excremento con que el animal marca su territorio, 6 en este caso interpela al Otro como otra noción de realidad, otra dimensión de esta que está imposibilitado de reconocer sin destruirse a sí mismo.

En ello su radical temor, lo que el estallido pone en cuestión es el mismo "modelo" y la producción de un malestar que se multiplica en connotaciones siendo imposible un discurso que se haga cargo de ese plus de significaciones del evento, 7 el plus que, sin embargo, se reconoce en el plano de las emociones y en el reencuentro con el espacio público, siempre avasallado en la historia de los últimos 50 años, por la represión y luego por el consumo.

Dejar la señal en el Otro que es incapaz de leer y que por el contrario, espera ansioso de borrar, de limpiar, de devolver a las estatuas su lugar, limpiar las paredes y dejarlas en el "orden natural de las cosas", para excluir esa amenaza social, ese sujeto de algún modo reprimido en un ambiente neoliberal, aunque parezca un oxímoron, debe responder a los códigos institucionales y se representa en las codificaciones que instala la cultura del poder, como manifestaciones de una violencia irracional, inmanejable, y que demanda de los grupos derechistas la figura mitológica de Pinochet, como una figura divina y presente en la sensibilidad de la derecha, una figura onírica que permitiría volver al orden de las cosas. Al cofre protegido de la identidad nacional como el mismo dictador lo definió; "barrer" con el lumpen, liquidar por la fuerza lo que aparece como pura irracionalidad para el privilegio, con la animalidad que contamina la convivencia social, suprimiendo de tal manera al sujeto que irrumpe en la escena social bajo la rabia, bajo el malestar que ha provocado la actual forma de vida. ${ }^{2}$

Son otros tiempos, otras señales. El estallido es la señal más poderosa de estos nuevos rumbos.

\footnotetext{
5 Ver los trabajos de etología de Konrad Lorenz (2015) y de Carles Riba (1990).

6 En cánidos el marcaje oloroso es un fenómeno bien documentado (Kleiman, 1966; Fox y Cohen, 1977). Los lobos, para marcar el territorio, recurren al marcaje olorosovisual: orina, rascadas en el suelo y secreciones de las glándulas anales, generalmente depositadas sobre las heces (Mech, 1970; Peters y Mech, 1975; Rothman y Mech, 1979; Barja, 2003).

7 Las referencias lacanianas a estos conceptos que se rearticulan en el análisis retórico de la política que hace Ernesto Laclau (2014).

8 Ver las fotos de limpieza o la misma imagen de Piñera en la época del covid 19, sacándose fotos en el centro icónico de la protesta social, en la Plaza Dignidad. Ver las declaraciones iniciales de la Junta Militar en 1973, donde las metáforas del cáncer eran formas de identificación a la oposición o al "enemigo" que había que "extirpar del cuerpo de Chile".
} 


\section{Bibliografía}

Bajtín, M. (2011): Las Fronteras del Discurso. Buenos Aires, Las Cuarenta.

Bajtín, M. (1981): The dialogic imagination. Austin, University of Texas Press.

Barja, I. (2003): “Patrones de señalización con heces en el lobo ibérico”, Etología, 11, pp. 1-7

Barthes, M. (2015): "Éléments de sémiologie", en R. Barthes, L'aventure sémiologique. Paris, Seuil, pp. 19-84.

Barthes, R. (1964): “Rhétorique de l’image”, Communications, 4, pp. 40-51.

Canetti, E. (2013): Masa y poder. Madrid, Alianza.

Deleuze, G. (1989): Logique du sens. Paris, De Minuit.

Deleuze, G. y F. Guattari (2013): Mille plateaux. Paris, De Minuit.

Eliade, M. (1980): Las religiones en sus textos. Vol IV. Historia de las creencias y de las ideas religiosas. Madrid, Ediciones cristiandad.

Fox, M. y J. Cohen (1977): “Canid communication”, en T. Sebeok. (ed.), How Animals Communicate. Bloomington, Indiana University Press, pp. 728-748.

Greimas, A. y J. Courtés (1990): Semiótica. Diccionario razonado de la teoría del lenguaje. Madrid, Gredos.

Greimas, A. (1976a): "Sémiotique et communications sociales", en A. Greimas, Sémiotique et sciences sociales. Paris, Seuil, pp. 45-60

Greimas, A. (1976b): "Pour une sémiotique topologique", en A. Greimas, Sémiotique et sciences sociales. Paris, Seuil, pp. 129-157.

Kleiman, D. (1966): "Scent marking in the canidae", Symp. Zool. Soc. London, 18, pp. 167-177.

Laclau, E. (2014): Los fundamentos retóricos de la sociedad. Buenos Aires, Fondo de Cultura Económica.

Le Breton, D. (2018): Elogio del caminar. Madrid, Siruela. 
Lorenz, K. (2015): Sobre la agresión. El pretendido mal. Madrid, Siglo XXI.

Lotman, I. (2000): La Semiosfera. Vol. III Semiótica de las Artes y de la Cultura. Valencia, Cátedra.

Lotman, I. (2009): “La caza de brujas: Semiótica del miedo”, en D. Navarro (ed.), El pensamiento cultural ruso en Criterios 1972-2008, Vol. 1. La Habana, Centro Teórico Cultural Criterios, pp. 14-34.

Marsciani, F. (2016): Tracciati di etnosemiotica. Milán, Franco Angeli.

Mech, L. D. (1970): The wolf: ecology and behavior of an endangered species. Garden City, Natural History Press.

Peters, R. y L. D. Mech (1975): “Scent-marking in Wolves”, American Scientist, 63, pp. 628-637.

Programa de Fomento de las Políticas Urbanas y de Suelo, Universidad Católica de Chile (ProUrbana) y Observatorio Social de la Universidad Alberto Hurtado (OSUAH) (2006): Preferencias de regulación urbana en Chile. Encuesta a residentes de las áreas metropolitanas de Santiago, Valparaíso y Concepción.

Riba, C. (1990): La comunicación animal, un enfoque zoosemiótico. Barcelona, Anthropos.

Rodríguez-Plaza, P. (2011): Estética urbana y mayorías latinoamericanas. Santiago, Ocho Libros.

Rodríguez-Plaza, P. (2001): "La pintura callejera chilena. Manufactura estética y territorialidad", Aisthesis, 34, pp. 171-184.

Rothman, R. y L. D. Mech (1979): “Scent-marking in lone wolves and newly formed pairs", Animal Behaviour, 27, pp. 750-760.

Sabatini, F., G. Cáceres y J. Cerda (2001): "Segregación residencial en las principales ciudades chilenas: tendencias de las tres últimas décadas y posibles cursos de acción”, Eure, 27 (82), pp. 21-42.

Sabatini, F. e I. Brain (2008): "La segregación, los guetos y la integración social urbana: mitos y claves”, Eure, 34 (103), pp. 5-26. 
Schütz, A. (1995): El problema de la realidad social. Buenos Aires, Amorrortu.

Verón, E. (1987): La semiósis sociale. Fragments d'une théorie de la discursivité. Paris, Presses Universitaires de Vincennes.

Fecha de recepción: 7 de septiembre de 2020

Fecha de aceptación: 21 de noviembre de 2020 